\title{
New Ways of Understanding Membranous Nephropathy
}

\author{
Hernando Trujillo ${ }^{a, b}$ Marina Alonso ${ }^{c}$ Manuel Praga ${ }^{a, b, d}$ \\ aDepartment of Nephrology, University Hospital "12 de Octubre", Madrid, Spain; bInvestigation Institute of \\ University Hospital "12 de Octubre" (imas12), Madrid, Spain; 'Department of Pathology, University Hospital \\ "12 de Octubre", Madrid, Spain; ${ }^{\text {d} D e p a r t m e n t ~ o f ~ M e d i c i n e, ~ C o m p l u t e n s e ~ U n i v e r s i t y, ~ M a d r i d, ~ S p a i n ~}$
}

\section{Keywords}

Glomerulonephritis · Nephrotic syndrome · Membranous nephropathy · Phospholipase A2 receptor - Autoimmune diseases

\begin{abstract}
Background: In the last decade, great advances have been made in the field of membranous nephropathy (MN). The autoimmune nature of the disease has been confirmed with the description of diverse antigens, and few but very important prospective trials regarding treatment alternatives have been published, changing profoundly the way we understand this entity. Nowadays, an individualized therapeutic scheme based on clinical and serologic data appears to be the most appropriate method to manage patients with MN. Although there is still a long way to go, it is expected that future scientific progress will enable a patient-centered medicine based on concept-driven therapies. Summary: MN is the most common cause of nephrotic syndrome (NS) in white adults. Approximately one-third of patients achieve spontaneous remission, one-third remain stable, and onethird have an aggressive course with persistent NS and deterioration of renal function. About $80 \%$ of patients have circulating autoantibodies to phospholipase $\mathrm{A} 2$ receptor 1 . Numerous therapies have been described including alkylating
\end{abstract}

agents, rituximab, and calcineurin inhibitors, but new drugs are currently being explored. Here, we review the most important aspects regarding $\mathrm{MN}$ with an emphasis on results of the most recent clinical trials and pathophysiologic advances. Key Messages: 1. Evolving pathophysiologic concepts and recently published clinical trials have deeply changed our view of MN. 2. Most patients with MN present autoantibodies against diverse glomerular antigens. 3. Currently, an individual patient-centered management based on clinical and serologic markers is the most adequate approach to treat patients with MN.

(c) 2020 S. Karger AG, Basel

\section{Introduction}

Membranous nephropathy (MN) refers to a histologic pattern shared by different etiologies characterized by thickening of the glomerular basement membrane (GBM) due to deposition of subepithelial immune complexes [1]. Since the description of antibodies against M-type phospholipase A2 receptor 1 (PLA2R1) [2], the term idiopathic MN has been gradually replaced by the more appropriate term primary membranous nephropathy (PMN). Approximately $70-85 \%$ of patients with PMN have circulating autoantibodies against PLA2R1, and another 3-5\%

$\begin{aligned} & \text { karger@karger.com } \\ & \text { www.karger.com/nef }\end{aligned}$
Karger ${ }^{\prime /}$

Dr. Manuel Praga

Department of Nephrology, University Hospital "12 de Octubre"

Ave. Córdoba km 5.400

ES-28041 Madrid (Spain)

mpragat@senefro.org 
have autoantibodies against thrombospondin type-1 domain-containing 7A (THSD7A) [2-4]. On the other hand, approximately $20-25 \%$ of cases are collectively referred to as secondary $M N$ as these cases have a recognizable etiology $[5,6]$. Recently, new antigens against exostosin 1 (EXT1)/exostosin 2 (EXT2) and neural epidermal growth factor-like 1 protein (NELL-1) were identified in a subgroup of patients with PLA2R1-negative $\mathrm{MN}[7,8]$.

Although a rare disease, $\mathrm{MN}$ is the most common cause of nephrotic syndrome (NS) in adults, accounting for $20-40 \%$ of cases $[3,9,10]$. Its incidence is estimated at 1.2 per 100,000 persons per year and has a $2: 1$ male predominance $[3,11]$. The most common clinical presentation is overt NS, but in $20 \%$ of cases it presents with nonnephrotic proteinuria and an insidious course [12-14]. Prognosis is variable, with approximately $30 \%$ of affected patients reaching spontaneous remission (SR), one-third remaining stable, and one-third presenting with persistent NS $[15,16]$. In those who continue to have NS, ESRD may develop in about half of patients over a 10 -year period $[17,18]$.

All patients with $\mathrm{MN}$ should be treated with optimal supportive care with the main goal of reducing proteinuria. The ideal time for initiation of immunosuppressive therapy, the type of drug, and the subset of patients who benefit from immunosuppression are still a matter of debate. Historically, alkylating agents plus steroids and calcineurin inhibitors (CNIs) have been the cornerstone of immunosuppression in $\mathrm{MN}$; however, since the first description of rituximab (RTX) use in patients with persistent NS [19], therapies that target B-cell lineages emerged as an attractive alternative option. In fact, the aforementioned study was published long before the description of anti-PLA2R1 antibodies, leading the way for the rationale of anti-CD20 antibody treatment even in subjects without evidence of nephritogenic autoantibodies. Moreover, in recent years, prospective clinical trials have demonstrated a beneficial role of RTX in patients with $\mathrm{MN}$ and nephrotic-range proteinuria $[18,20]$. Beyond a one-sizefits-all approach, it seems that at the present time, a personalized therapy should be applied based on antibody titers and clinical evolution.

\section{Pathogenesis: The Search for the Grail}

The development of the passive Heymann nephritis model in rats in 1959 marked the beginning of a new era in our understanding of MN [21]. Several years later, studies demonstrated that subepithelial immune deposi- tion could be produced in isolated kidneys of rats in the absence of circulating immune complexes, establishing the hypothesis of in situ complex formation [22]. This landmark observation led to the search for antigens in the GBM and the podocyte membrane. It was not until 2002 that the first description of a target antigen in $\mathrm{MN}$ was reported in an unusual case of a pregnant woman with anti-neutral endopeptidase antibodies that were transferred to her fetus, in which an aggressive form of $\mathrm{MN}$ developed antenatally [23]. But, certainly, the description of PLA2R1 as the main target antigen in the majority of patients with $\mathrm{MN}$ has been the most revolutionary discovery for our current pathophysiologic conception of the disease [2].

\section{Antibodies against PLA2R1}

PLA2R1 is a $185-\mathrm{kD}$ transmembrane glycoprotein with multiple extracellular domains which is normally expressed by human podocytes. At present, its exact physiologic role remains unclear. In the setting of antiPLA2R1-associated MN, antibodies (mainly IgG4) cross the glomerular capillaries and bind to the protein along the subepithelial side of the capillary wall, forming the typical subepithelial deposits observed in renal biopsies [2]. To date, the trigger (or triggers) for anti-PLA2R1 production is unknown [24]. Although the positivity of antiPLA2R1 is strongly indicative of a primary character, a few cases of secondary MN with positive anti-PLA2R1 antibodies have been described [25], possibly as a coincidental association.

The extracellular region of PLA2R1 consists of 10 domains, including a cysteine-rich domain (CysR), a fibronectin type II domain, and eight distinct C-type lectin domains (CTLD1-8). It has been demonstrated that the dominant epitope lies within the N-terminal CysR domain, but CTLD1 and CTLD7 can also be recognized in some cases [26, 27]. Seitz-Polski et al. [26] observed that patients with baseline multi-domain recognition (CysR, CTLD1, and CTLD7) presented a more severe disease than those who only had antibodies against CysR. However, some issues regarding multi-domain recognition remain elusive. It is unknown which antibodies develop first, whether the immune response is first directed against CysR and then spreads toward CTLD1/CTLD7, or whether the immune response is polyclonal from the beginning of the disease.

Spontaneous remission in patients with high baseline levels of anti-PLA2R1 is unlikely, especially if increasing levels are observed over time [28]. Also, disappearance of anti-PLA2R1 antibodies (immunological remission), ei- 
ther spontaneous or induced by immunosuppressive therapy, precedes clinical remission by a period of several months [29-31]. On the other hand, in cases where remission is achieved, reappearance of anti-PLA2R1 is predictive of clinical relapses $[28,31]$. Likewise, patients who fail to achieve complete immunological remission after immunosuppressive treatment are more likely to experience clinical relapses [32].

\section{Antibodies against THSD7A}

Another pathogenic glomerular autoantigen known as THSD7A has been identified in a small subset of patients (3-5\%) with MN [4]. THSD7A is a glycosylated $250-\mathrm{kD}$ type 1 transmembrane protein with a currently unknown physiologic function, although several of its features suggest a role in adhesion [27]. As in the case of PLA2R1, it induces an IgG4-predominant humoral immune response. Interestingly, murine data have shown that injection of serum from patients with antiTHSD7A antibodies induces proteinuria and promotes a histologic pattern of $\mathrm{MN}$, further supporting their pathogenic role in the development of MN [33]. Recently, description of the extracellular conformation of the protein identified 21 thrombospondin type 1 domains. In $90 \%$ of cases, recognition of multiple epitope domains was observed, with a predominance of the first and second $\mathrm{N}$-terminal domains. Interestingly, in cases where recognition of $\geq 3$ epitope domains was detected, titers of anti-THSD7A antibodies were higher than in those patients with recognition of less epitope domains(similar to the case of anti-PLA2R1 MN). Moreover, loss of epitope recognition during follow-up was associated with decreasing titers of antibodies and reduction of proteinuria [34].

Anti-THSD7A-associated MN has been linked to malignant neoplasms [35, 36]. In some cases, the association seems to be well-defined as anti-THSD7A antibodies have been detected concomitantly both in the tumor and in infiltrated lymph nodes $[37,38]$.

\section{Antibodies against EXT1/EXT2 and NELL-1}

The most recently identified glomerular proteins involved in MN are EXT1/ EXT2 and NELL-1. Sethi et al. [7] identified antibodies against EXT1/EXT2 in the GBM of 21 patients with PLA2R-negative MN using laser microdissection, mass spectrometry and immunohistochemistry. All control cases tested negative for EXT1/ EXT2. Noteworthy, 70\% of the cases had positive autoimmune serologic parameters, $35 \%$ had lupus, and more than $80 \%$ of positive EXT1/EXT2 biopsies showed fea- tures suggestive of secondary MN. Circulating antibodies against EXT1/EXT2 were not detected in any case, although very few patients had available serum. The authors proposed that EXT1/EXT2 proteins may represent biomarker proteins for MN associated with autoimmune disease rather than target antigens [7].

In a recent collaborative study using similar methods [8], 29 PLA2R1-negative cases showed positivity for NELL-1. These deposits co-localized with IgG in the GBM. Interestingly, clinical and histologic features of $\mathrm{PMN}$ were observed in all cases, although the most frequently encountered immunoglobulins were IgG1, IgG3 and IgG2. All controls stained negative for NELL-1. Of note, 5 patients had positive NELL-1 Western blot analysis in serum with no reactivity observed in controls. Additionally, 5 cases of double negative (PLA2R1/THSD7A) MN resulted NELL-1 positive in two validation cohorts, confirming a new distinct type of PMN.

\section{Other Antibodies}

The remaining cases with histologic features of PMN but absence of antibodies against PLA2R1, THSD7A, or NELL-1 (in serum and/or kidney biopsy) are probably caused by autoantibodies against as yet unidentified specific antigens. A possible role of anti-aldose reductase and anti-manganese superoxide dismutase autoantibodies has been suggested [39]. In addition, in the pediatric population, immunization against bovine serum albumin has been proposed as a potential cause of $\mathrm{MN}$ [40].

In the case of secondary $\mathrm{MN}$, it has been hypothesized that implicated antigens are deposited between the GBM and podocytes and, subsequently, bound by circulating antibodies, or that antigens may form circulating immune complexes that are subsequently trapped in glomerular capillaries or may dissociate and reform in the subepithelial space $[1,40,41]$.

\section{The Complement System}

Several previous and recent observations indicate that the complement system plays a paramount role in the pathophysiology of MN, especially the terminal complement components C5b-9 (membrane-attack complex). It has been shown that there is an elevated urinary excretion of the C5b-9 complex in $\mathrm{MN}$ and disease progression correlates with ongoing urinary loss $[6,42]$. Additionally, in cases of anti-neutral endopeptidase-associated $\mathrm{MN}$, a relationship between the neutral endopeptidase system and the activation of complement within immune deposits and the generation of C5b-9 has been described [23, 43]. Recently, Seikrit et al. [44] reported an interesting case of 
Table 1. Causes of secondary MN (adapted from Couser WG [3])

\begin{tabular}{ll}
\hline Group & Conditions \\
\hline $\begin{array}{l}\text { Autoimmune } \\
\text { diseases }\end{array}$ & $\begin{array}{l}\text { Systemic lupus erythematosus, Hashimoto's disease, Graves' disease, diabetes mellitus, rheumatoid arthritis, } \\
\text { Sjögren syndrome, dermatomyositis, mixed connective tissue disease, ankylosing spondylitis, primary biliary } \\
\text { cirrhosis, bullous pemphigoid, retroperitoneal fibrosis, Guillain-Barré syndrome, graft-versus-host disease, bone } \\
\text { marrow and stem cell transplantation, anti-GBM disease, IgA nephropathy, ANCA-associated vasculitis, IgG4 } \\
\text { disease, renal transplantation }\end{array}$ \\
\hline Cancer & $\begin{array}{l}\text { Lung and bronchus, gastric, renal, prostatic, breast, colorectal, plasma cell dyscrasias, non-Hodgkin lymphoma, } \\
\text { chronic lymphocytic leukemia, mesothelioma, melanoma }\end{array}$ \\
\hline Infections & Hepatitis B, hepatitis C, HIV, syphilis, schistosomiasis, malaria, filariasis, hydatid disease, leprosy \\
\hline Drugs/toxins & $\begin{array}{l}\text { NSAIDs, penicillamine, gold, captopril, bucillamine agents, probenecid, anti-TNF- } \alpha, \text { mercury, lithium, } \\
\text { formaldehyde, hydrocarbons }\end{array}$ \\
\hline
\end{tabular}

MN, membranous nephropathy; GBM, glomerular basement membrane; NSAIDs, nonsteroidal anti-inflammatory drugs; TNF- $\alpha$, tumor necrosis factor- $\alpha$; IgA, immunoglobulin A.

a patient with anti-PLA2R1-associated $\mathrm{MN}$ and antibodies against complement factor $H$, an important regulator of the alternative complement pathway. However, a subsequent study did not support the hypothesis that such antibodies contribute to hyperactivation of the complement system in the setting of MN [45].

Evidence suggests that the lectin pathway is responsible of complement activation in PMN because IgG4 is unable to activate the classic complement pathway $[6,46$, 47]. Nonetheless, the mechanism by which this activation takes place remains speculative.

\section{Secondary MN}

In about $20 \%$ of patients with $\mathrm{MN}$, an underlying cause may be identified [3]. The most frequent etiologies include autoimmune diseases, cancer, infections and drugs (Table 1). In many cases, treatment of the primary disease leads to resolution of the nephrotic syndrome. $\mathrm{MN}$ is the most common paraneoplastic glomerulopathy associated with solid tumors [48]. Approximately $10 \%$ (up to $25 \%$ after age 60 years) of adult patients with $\mathrm{MN}$ have a malignancy at the time of renal biopsy or within a year thereafter $[1,49]$. Noteworthy, in some cases, the association may be coincidental rather than causal [50].

Histologic findings that should raise suspicion of secondary MN include preponderant deposition of IgG1 or IgG3, positivity for C1q or EXT1/EXT2, mesangial and subendothelial deposits, cellular proliferation in the glomeruli and endothelial tubuloreticular inclusions [7, $9,10]$.

\section{Diagnosis: To Biopsy or Not to Biopsy, That Is the Question}

Renal biopsy remains the gold standard for the diagnosis of MN. However, this concept has been challenged in a recent study where a noninvasive diagnosis based on anti-PLA2R1 testing was suggested for a specific subset of patients. The authors found that in patients with positive anti-PLA2R1 antibodies and preserved renal function, with no evidence of secondary causes, kidney biopsy did not provide any considerable information leading to changes in management [51].

Histologic lesions and stages of MN, with the exception of tubulointerstitial fibrosis, have a poor correlation with prognosis and treatment response. Moreover, antiPLA2R1 provides an accurate diagnosis of PMN because these antibodies are not detected in other renal diseases or healthy patients. Nonetheless, one should consider that genetic and molecular data from kidney biopsies could be useful to identify potential prognostic markers and new therapeutic targets. While awaiting prospective validation studies, some authors suggest applying a noninvasive approach only in those patients with a clear contraindication for renal biopsy [52]. The main pathologic findings in $\mathrm{MN}$ are presented in Figure 1.

\section{Treatment: A Holistic Approach}

Antiproteinuric treatment with angiotensin-converting enzyme inhibitors or angiotensin receptor blockers is the cornerstone of supportive therapy in MN. Beneficial 

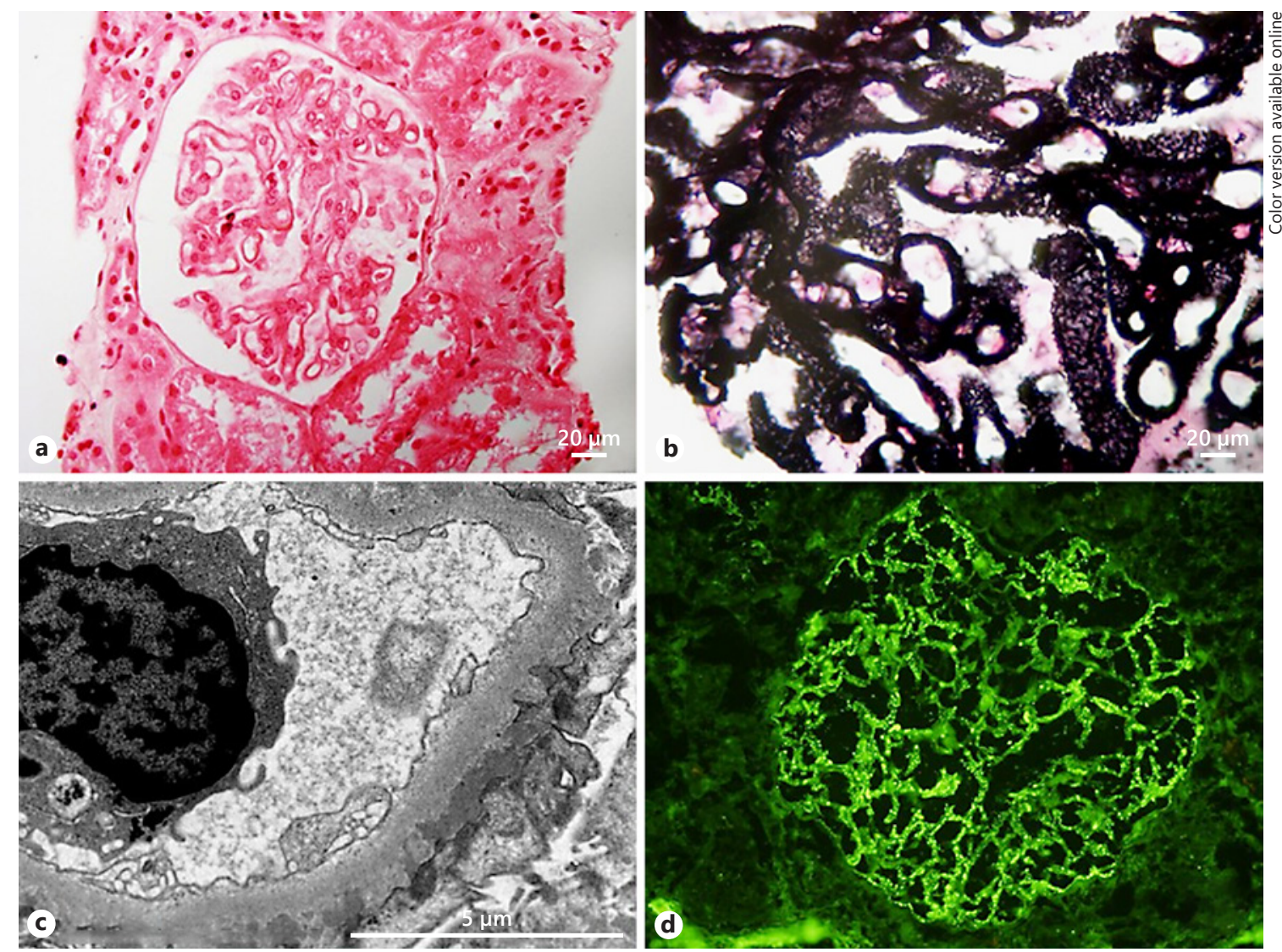

Fig. 1. Main pathologic findings in MN. a Thickened glomerular capillary loops with a rigid appearance (hematoxylin and eosin, $40 \times$ ). b GBMs with pinpoint lucencies and "spikes" (silver methenamine, $100 \times)$. c Electron micrograph showing subepithelial homogeneous electron-dense deposits and podocyte foot process ef- facement in adjacent areas. d Immunofluorescence microscopy showing finely granular staining for IgG in the subepithelial side of the GBM (IgG, 40×). MN, membranous nephropathy; GBM, glomerular basement membrane. effects of these drugs include mitigation of glomerular hypertension and improvement of glomerular barrier size selectivity [53, 54]. However, these positive effects seem to have less impact on patients with heavy proteinuria [55]. Supportive treatment should also include statins (for dyslipidemia), hypoproteic diet, salt restriction, and diuretics as needed $[3,10,54]$. The decision of adding prophylactic anticoagulation should be based on an individual's bleeding risk profile. In general, it is recommended in cases of severe hypoalbuminemia $(<2.5 \mathrm{~g} / \mathrm{dL})$, especially when other risk factors for thrombosis are present $[56,57]$.

Because SR is a well-known characteristic of PMN [15], previous recommendations were to start immunosuppressive therapy only in those patients with persisting NS (or life-threatening manifestations of NS) after 6 months of follow-up. However, this approach lacks specificity as a substantial proportion of such patients may still develop SR [58]. On the other hand, patients with high levels of anti-PLA2R1 or multi-domain recognition have a very low probability of developing SR and an increased risk of relapses. Hence, at present, stratification based on several risk factors appears as the most adequate approach to decide which patients benefit from immunosuppression (Table 2). In fact, according to recent recommendations, early initiation ( $<6$ months) of immunosuppressive therapy may be considered in patients at increased risk of disease progression $[1,58]$. Nonetheless, when contemplating this strategy, the potential risk of serious adverse events associated with immunosuppressive drugs such as alkylating agents and CNIs must be carefully addressed [59, 60]. 
Table 2. Factors associated with high risk of progression (adapted from Floege et al. [58])

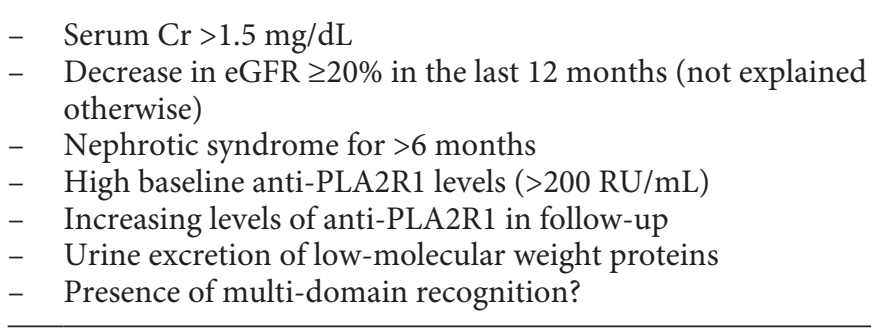

eGFR, estimated glomerular filtration rate; PLA2R1, phospholipase A2 receptor 1 .

\section{Immunosuppressive Therapy}

Treatment with steroids plus cyclical alkylating agents (cyclophosphamide [CYC] or chlorambucil) is a highly effective therapy for patients with $\mathrm{MN}$ at high risk of progression. Complete or partial remission is achieved in 70$93 \%$ of cases at $2-3$ years [61-64]. CYC is preferred over chlorambucil because of a better safety profile. However, CYC has also been associated with severe side effects such as infections, cancer and infertility [59]. The modified Ponticelli regimen entails approximately $9-13 \mathrm{~g}$ of CYC for a 70-kg adult, while the Dutch protocol entails more than $30 \mathrm{~g}$ (Table 3). Interestingly, a protocol of monthly intravenous CYC plus oral prednisone proved to be effective in two small retrospective studies, with a cumulative CYC dose of 5-10 g $[65,66]$.

CNIs (cyclosporine [CsA] and tacrolimus) have also proved to be effective, attaining complete or partial remission in $70-85 \%$ of cases after 6-12 months of therapy [67-69]. The main drawbacks of these agents are the high relapse rate $(40-50 \%)$ after treatment discontinuation and the risk of chronic nephrotoxicity. However, multicenter observational studies have shown that relapse risk is associated with the duration of the tapering period. The shorter the tapering period, the higher the risk of relapse [70]. On the other hand, the amount of residual proteinuria at the onset of CNI tapering in patients who achieve partial response has also been associated with a higher risk of relapses [70]. Interestingly, observational studies have reported that RTX administered at the onset of CNI tapering can prevent relapses [71].

RTX (anti-CD20 chimeric antibody) is currently the most promising agent for treatment of MN. Previous studies have reported complete or partial remission rates in about $60-65 \%$ of cases, with a median time to remission of approximately 7 months $[20,30,72]$. In a recent prospective randomized trial, the MENTOR investigators reported that RTX was superior to CsA in maintaining proteinuria remission in patients with $\mathrm{MN}$ and high risk of progression [18]. After 24 months, $60 \%$ of patients in the RTX group versus $20 \%$ in the CsA group had complete or partial remission. In patients with positive antiPLA2R1, the decline in antibody levels was faster and of greater magnitude and duration in the RTX group. As previously observed by other authors [73], the MENTOR confirmed that patients with very high anti-PLA2R1 levels are less likely to respond to RTX (only $31.3 \%$ of patients in the high tertile responded to RTX at the end of follow-up).

The optimal dose of RTX and the need for re-treatment are still a matter of debate. Several protocols have been used, including $1 \mathrm{~g}$ at 2-week intervals, two infusions of $375 \mathrm{mg} / \mathrm{m}^{2}$ at 1 -week interval and a single infusion of $375 \mathrm{mg} / \mathrm{m}^{2}$. A recent study suggests that $1 \mathrm{~g}$ at 2 -week intervals is more effective than two infusions of $375 \mathrm{mg} / \mathrm{m}^{2}$ at 1-week interval [74]. Interestingly, findings from a small single-center study suggest that a B-cell-driven strategy could avoid exposure to repeated courses of RTX that would unnecessarily increase treatment costs and risk of adverse effects and sensitization [75]. In the MENTOR trial, patients in the RTX group received $1 \mathrm{~g}$ at 2 -week intervals with a second course at 6 months in cases where proteinuria was reduced from baseline (at least $25 \%)$, but there was not complete remission. In the CsA arm, if proteinuria was reduced (at least 25\%), treatment was continued for an additional 6 months, then tapered, and discontinued after 2 months. It is important to emphasize that at month 12 , there were no significant differences between both treatment arms regarding the number of responses (60\% vs. $52 \%)$ [18] and that the poor results in the CsA arm were most likely due to the rapid discontinuation of the drug, contravening previously agreed recommendations [76]. Noteworthy, none of the patients in the RTX arm had complete remission at 6 months; therefore, all patients with significant reduction of proteinuria were re-treated [18]. One important consideration is that RTX is lost in the urine in patients with NS compared to non-proteinuric subjects [77]. Also, interindividual variability of residual RTX serum levels may depend on the efficacy of recycling by endothelial cells via FcRn receptors, which might be influenced by polymorphisms in FcRn [78].

Two ongoing controlled clinical trials (STARMEN [NCT01955187] and RI-CYCLO [NCT03018535]) are comparing the efficacy of RTX versus the modified Ponticelli regimen. Results from these studies will give more 
Table 3. Summary of immunosuppressive protocols in PMN (adapted from Couser WG [3])

\begin{tabular}{|c|c|}
\hline Pharmacologic agent & Doses \\
\hline \multicolumn{2}{|l|}{ Alkylating agents } \\
\hline Ponticelli regimen & $\begin{array}{l}\text { Months 1, 3, and 5: } 1 \mathrm{~g} / \mathrm{d} \text { i.v. MPDN } \times 3 \mathrm{~d} \text {, followed by oral PDN } 0.5 \mathrm{mg} / \mathrm{kg} / \mathrm{d} \times 27 \mathrm{~d} \\
\text { Months 2, 4, and 6: oral CHL } 0.2 \mathrm{mg} / \mathrm{kg} / \mathrm{d} \times 30 \mathrm{~d}\end{array}$ \\
\hline Modified Ponticelli & $\begin{array}{l}\text { Months 1, 3, and 5: } 1 \mathrm{~g} / \mathrm{d} \text { i.v. MPDN } \times 3 \mathrm{~d} \text {, followed by oral PDN } 0.5 \mathrm{mg} / \mathrm{kg} / \mathrm{d} \times 27 \mathrm{~d} \\
\text { Months 2, 4, and 6: oral CYC } 2-2.5 \mathrm{mg} / \mathrm{kg} / \mathrm{d} \times 30 \mathrm{~d}\end{array}$ \\
\hline Dutch regimen & $\begin{array}{l}\text { Months } 1,3 \text {, and } 5: 1 \mathrm{~g} / \mathrm{d} \text { i.v. MPDN } \times 3 \mathrm{~d} \text {, followed by oral PDN } 0.5-1 \mathrm{mg} / \mathrm{kg} / \mathrm{d} \times 6 \\
\text { months (then taper) plus oral CYC } 1.5-2 \mathrm{mg} / \mathrm{kg} / \mathrm{d} \times 12 \text { months }\end{array}$ \\
\hline \multicolumn{2}{|l|}{ Calcineurin inhibitors } \\
\hline Tacrolimus & $\begin{array}{l}0.05-0.075 \mathrm{mg} / \mathrm{kg} / \mathrm{d} \times 12 \text { months (through levels } 5-7 \mathrm{ng} / \mathrm{mL} \text { ), then taper over } 6-12 \\
\text { months } \pm \text { low-dose PDN }\end{array}$ \\
\hline Cyclosporine & $\begin{array}{l}3.5-5.0 \mathrm{mg} / \mathrm{kg} / \mathrm{d}(\text { through levels } 120-200 \mathrm{ng} / \mathrm{mL}) \times 12 \text { months, then taper over } 6-12 \\
\text { months } \pm \text { low-dose PDN }\end{array}$ \\
\hline \multicolumn{2}{|l|}{$B$ cell targeted } \\
\hline Rituximab & $\begin{array}{l}1 \mathrm{~g} \text { i.v. } \times 2(\text { days } 1 \text { and } 15) \pm \text { repeated course at } 6 \text { months } \\
375 \mathrm{mg} / \mathrm{m}^{2} \times 2(\text { at } 1 \text {-week interval }) \\
375 \mathrm{mg} / \mathrm{m}^{2} \text { i.v. every week } \times 4 \text { weeks } \\
375 \mathrm{mg} / \mathrm{m}^{2} \text { i.v. single dose and follow B-cell counts }\end{array}$ \\
\hline
\end{tabular}

i.v., intravenous; MPDN, methylprednisolone; PDN, prednisone; CHL, chlorambucil; CYC, cyclophosphamide.

insights about the efficacy of RTX compared to traditional immunosuppressive therapy.

Adrenocorticotrophic hormone and mycophenolate mofetil have also been tested for treatment of MN. However, data on their efficacy and safety comes mostly from small clinical trials, some of them observational [79-83]. Thus, the possible role of these agents in the management of $\mathrm{MN}$ remains to be established.

\section{Future Alternatives}

New-generation anti-CD20 monoclonal antibodies such as ofatumumab (OFA) are an attractive alternative option in patients with resistance or sensitization to RTX [54]. As OFA binds to both the small and large extracellular loops of the CD20 molecule, its activity against RTXresistant cells is believed to be due to the proximal epitope of the small loop and the high capacity for complement activation [84]. To date, there are no controlled studies with OFA in patients with MN.

Belimumab (monoclonal antibody that targets the soluble form of B lymphocyte stimulator) was tested in a small recently published study [85], with a positive but very slow clinical and immunological response in the majority of cases. The authors proposed that a combination of belimumab and other therapies merits further study. It is believed that memory plasma cells could play a role in resistant cases of MN. In fact, bortezomib (proteasome inhibitor) has shown to be effective in some case reports [86], and studies with anti-CD38 antibodies are expected to start recruiting patients soon (NCT04145440).

Complement blockade seems to be a logical approach for treatment of MN. Eculizumab failed to significantly reduce proteinuria in an unpublished randomized clinical trial, although possibly as a result of underdosing [54]. However, drugs that block the complement system at other levels are currently being explored in patients with MN (NCT04154787).

\section{One Size Does Not Fit All}

More than a "one drug to rule them all" approach, the diversity of the immunosuppressive armamentarium in PMN should be seen as a great strength because probably not all patients need to be treated equally. The rate of partial remission is lower with RTX than with CYC [59]. Also, RTX is less effective in inducing immunological remission in patients with high levels of anti-PLA2R1 or multi-domain recognition $[73,74]$, although the majority of these cases seem to respond to a second RTX course [87]. Therefore, the modified Ponticelli regimen appears as the most suitable therapy for patients with an aggres- 


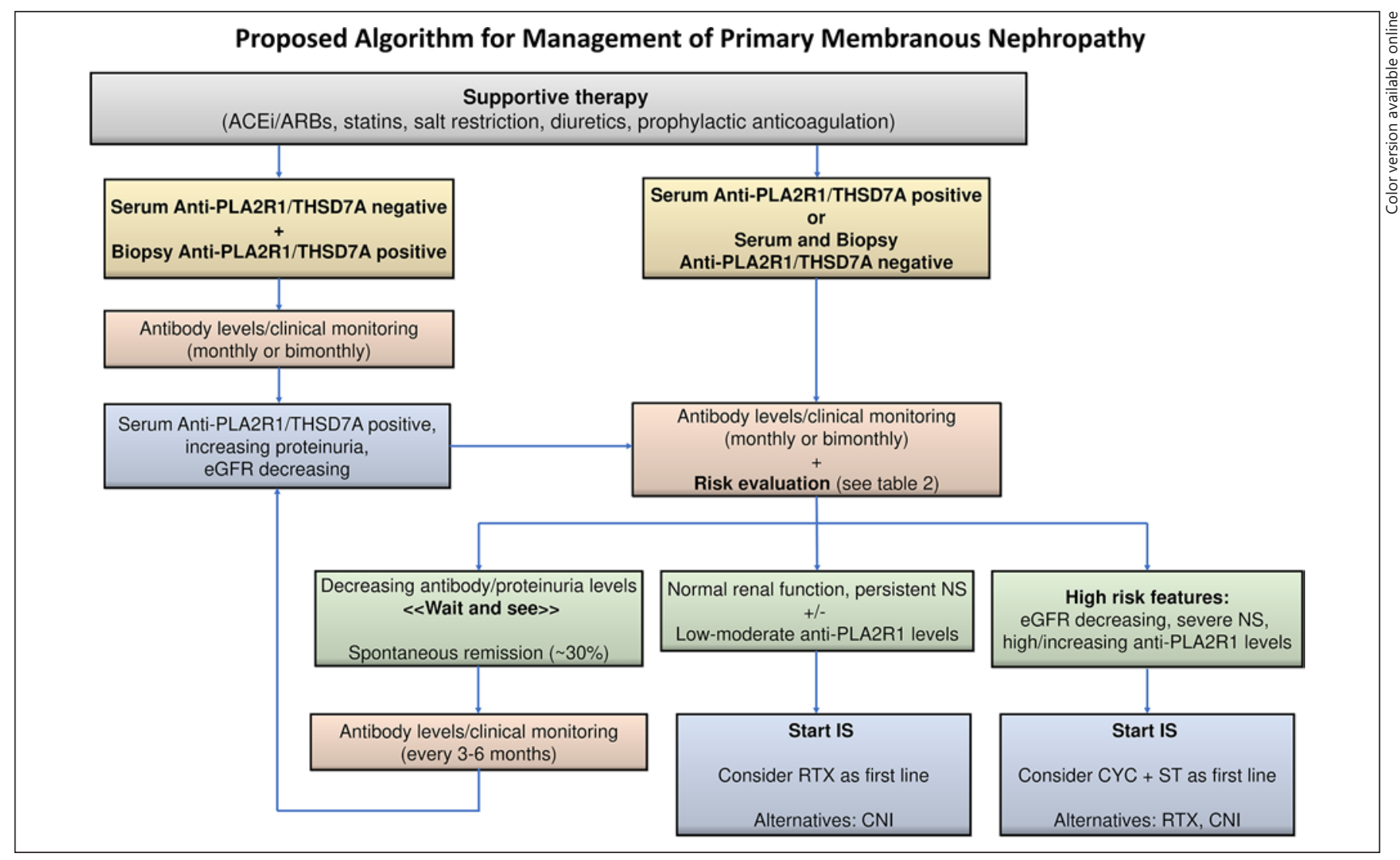

Fig. 2. ACEi, angiotensin-converting enzyme inhibitors; ARBs, angiotensin receptor blockers; eGFR, estimated glomerular filtration rate; NS, nephrotic syndrome; RTX, rituximab; CNIs, calcineurin inhibitors; CYC, cyclophosphamide; ST, steroids; levels of anti-PLAR1: low $=14-100 \mathrm{RU} / \mathrm{mL}$, moderate $=101-200 \mathrm{RU} / \mathrm{mL}$, high $=$ $>200 \mathrm{RU} / \mathrm{mL}$ (ELISA, EuroImmune) [58]; severe nephrotic syndrome = persistent proteinuria $>8 \mathrm{~g} / 24 \mathrm{~h}$ with hypoalbuminemia $<3 \mathrm{~g} / \mathrm{dL}$; rationale for proposed immunosuppressive treatment can be found in refs. 18, 59, $67-69,72,73$, and 86-88.

sive disease. Instead, if RTX is chosen for treating severe disease, one should consider using a high-dose regimen ( $1 \mathrm{~g}$ at 2 -week intervals repeated at 6 months) rather than moderate or low doses in view of recent findings $[18,74$, 87]. Notably, some studies have suggested that RTX is effective in patients with partial or no response to previous immunosuppressive treatment $[72,88]$.

An interesting alternative for future prospective trials would be to "modernize" the modified Ponticelli regimen by using cyclical intravenous CYC (entailing lower cumulative doses than oral CYC) $[65,66]$, lower steroid doses, or combined RTX plus CYC regimens [89]. CNIs are another option, either associated with steroids or as monotherapy [76]. The high rate of relapses after discontinuation can be prevented by a slow tapering $[70,76]$ or by adding RTX at the onset of CNI tapering $[71,78]$. This therapeutic approach is being evaluated in the STARMEN trial. A proposed algorithm for the management of PMN is presented in Figure 2.

\section{Conclusion}

$\mathrm{MN}$ is a relatively common autoimmune disease with a heterogeneous prognosis. In the last decade, advances in our knowledge of disease mechanisms have yielded new diagnostic and therapeutic approaches, opening the way to personalized medicine. Although many issues remain to be unraveled, we anticipate that future research will focus on a better understanding of autoantibodies and target antigens that may help predict disease course, as well as on more specific and safer therapeutic regimens. 


\section{Disclosure Statement}

The authors have no conflicts of interest to declare.

\section{Funding Sources}

This study was supported by Red de Investigación Renal (RedInRen; RD12/0021/0029) (M.P.).

\section{Author Contributions}

Hernando Trujillo and Manuel Praga wrote the manuscript and provided data for Tables $1-3$ and Figure 2. Marina Alonso provided images and data for Figure 1. All authors reviewed the final manuscript.

\section{References}

1 De Vriese AS, Glassock RJ, Nath KA, Sethi S, Fervenza FC. A proposal for a serology-based approach to membranous nephropathy. J Am Soc Nephrol. 2017;28(2):421-30.

2 Beck LH, Bonegio RG, Lambeau G, Beck DM, Powell DW, Cummins TD, et al. M-type phospholipase A2 receptor as target antigen in idiopathic membranous nephropathy. $\mathrm{N}$ Engl J Med. 2009;361(1):11-21.

3 Couser WG. Primary membranous nephropathy. Clin J Am Soc Nephrol. 2017;12(6):98397.

4 Tomas NM, Beck LH, Meyer-Schwesinger C, Seitz-Polski B, Ma H, Zahner G, et al. Thrombospondin type-1 domain-containing $7 \mathrm{~A}$ in idiopathic membranous nephropathy. $\mathrm{N}$ Engl J Med. 2014;371(24):2277-87.

5 Ponticelli C, Glassock RJ. Glomerular diseases: membranous nephropathy: a modern view. Clin J Am Soc Nephrol. 2014;9(3):60916.

$6 \mathrm{Ma} \mathrm{H}$, Sandor DG, Beck LH. The role of complement in membranous nephropathy. Semin Nephrol. 2013;33(6):531-42.

7 Sethi S, Madden BJ, Debiec H, Charlesworth MC, Gross L, Ravindran A, et al. Exostosin 1/ exostosin 2-associated membranous nephropathy. J Am Soc Nephrol. 2019 Jun; 30(6):1123-6.

8 Sethi S, Debiec H, Madden B, Charlesworth MC, Morelle J, Gross L, et al. Neural epidermal growth factor-like 1 protein (NELL-1) associated membranous nephropathy. Kidney Int. 2020 Jan;97(1):163-74.

9 Ronco P, Debiec H. Pathophysiological advances in membranous nephropathy: time for a shift in patient's care. Lancet. 2015; 385(9981):1983-92.

10 Cattran DC, Brenchley PE. Membranous nephropathy: integrating basic science into improved clinical management. Kidney Int. 2017;91(3):566-74.

11 McGrogan A, Franssen CF, de Vries CS. The incidence of primary glomerulonephritis worldwide: a systematic review of the literature. Nephrol Dial Transplant. 2011;26(2): 414-30.

12 Glassock RJ. Diagnosis and natural course of membranous nephropathy. Semin Nephrol. 2003;23(4):324-32.
13 Cattran DC. Idiopathic membranous glomerulonephritis. Kidney Int. 2001;59(5):198394.

14 Fulladosa X, Praga M, Segarra A, Martínez Ara J. The treatment of membranous glomerulonefritis. Nefrologia. 2007;25(5):467-4.

15 Polanco N, Gutiérrez E, Covarsí A, Ariza F, Carreño A, Vigil A, et al. Spontaneous remission of nephrotic syndrome in idiopathic membranous nephropathy. J Am Soc Nephrol. 2010;21(4):697-04.

16 Fogo AB, Lusco MA, Najafian B, Alpers CE. AJKD atlas of renal pathology: membranous nephropathy. Am J Kidney Dis. 2015;66(3): e15-7.

17 Troyanov S, Wall CA, Miller JA, Scholey JW, Cattran DC; Toronto Glomerulonephritis Registry Group. Idiopathic membranous nephropathy: definition and relevance of a partial remission. Kidney Int. 2004;66(3):1199205.

18 Fervenza FC, Appel GB, Barbour SJ, Rovin BH, Lafayette RA, Aslam N, et al. Rituximab or cyclosporine in the treatment of membranous nephropathy. N Engl J Med. 2019;381: 36-46.

19 Remuzzi G, Chiurchiu C, Abbate M, Brusegan V, Bontempelli M, Ruggenenti P. Rituximab for idiopathic membranous nephropathy. Lancet. 2002;360(9337):923-4.

20 Dahan K, Debiec H, Plaisier E, Cachanado M, Rousseau A, Wakselman L, et al. Rituximab for severe membranous nephropathy: a 6-month trial with extended follow-up. J Am Soc Nephrol. 2017;28(1):348-58.

21 Heymann W, Hackel DB, Harwood S, Wilson SG, Hunter JL. Production of nephrotic syndrome in rats by Freund's adjuvants and rat kidney suspensions. 1951. J Am Soc Nephrol. 1959;11(1):183-8.

22 Couser WG, Steinmuller DR, Stilmant MM, Salant DJ, Lowenstein LM. Experimental glomerulonephritis in the isolated perfused rat kidney. J Clin Invest. 1978;62(6):1275-87.

23 Debiec H, Guigonis V, Mougenot B, Decobert F, Haymann JP, Bensman A, et al. Antenatal membranous glomerulonephritis due to anti-neutral endopeptidase antibodies. N Engl J Med. 2002;346(26):2053-60.
24 McQuarrie EP. Anti-phospholipase A2 receptor antibodies in primary membranous nephropathy-10 key points. Nephrol Dial Transplant. 2018;33(2):212-3.

25 Qin W, Beck LH, Zeng C, Chen Z, Li S, Zuo $\mathrm{K}$, et al. Anti-phospholipase A2 receptor antibody in membranous nephropathy. J Am Soc Nephrol. 2011;22(6):1137-43.

26 Seitz-Polski B, Debiec H, Rousseau A, Dahan K, Zaghrini C, Payré C, et al. Phospholipase A2 receptor 1 epitope spreading at baseline predicts reduced likelihood of remission of membranous nephropathy. J Am Soc Nephrol. 2018;29:401-8.

27 Beck LH. PLA2R and THSD7A: disparate paths to the same disease? J Am Soc Nephrol. 2017;28(9):2579-89.

28 Hofstra JM, Beck LH, Beck DM, Wetzels JF, Salant DJ. Anti-phospholipase A2 receptor antibodies correlate with clinical status in idiopathic membranous nephropathy. Clin J Am Soc Nephrol. 2011;6(6):1286-91.

29 Hoxha E, Thiele I, Zahner G, Panzer U, Harendza S, Stahl RA. Phospholipase A2 receptor autoantibodies and clinical outcome in patients with primary membranous nephropathy. J Am Soc Nephrol. 2014;25(6):1357-66.

30 Beck LH Jr, Fervenza FC, Beck DM, Bonegio RG, Malik FA, Erickson SB, et al. Rituximabinduced depletion of anti-PLA2R autoantibodies predicts response in membranous nephropathy. J Am Soc Nephrol. 2011;22(8): 1543-50.

31 Ruggenenti P, Debiec H, Ruggiero B, Chianca A, Pellé T, Gaspari F, et al. Anti-phospholipase $\mathrm{A} 2$ receptor antibody titer predicts postrituximab outcome of membranous nephropathy. J Am Soc Nephrol. 2015;26(10):254558.

32 Bech AP, Hofstra JM, Brenchley PE, Wetzels JF. Association of anti-PLA2R antibodies with outcomes after immunosuppressive therapy in idiopathic membranous nephropathy. Clin J Am Soc Nephrol. 2014;9(8):138692.

33 Tomas NM, Hoxha E, Reinicke AT, Fester L, Helmchen U, Gerth J, et al. Autoantibodies against thrombospondin type 1 domain-containing 7A induce membranous nephropathy. J Clin Invest. 2016;126(7):2519-32. 
34 Seifert L, Hoxha E, Eichhoff AM, Zahner G, Dehde S, Reinhard L, et al. The most N-terminal region of THSD7A Is the predominant target for autoimmunity in THSD7A-associated membranous nephropathy. J Am Soc Nephrol. 2018;29(5):1536-48.

35 Glassock RJ. Human idiopathic membranous nephropathy: a mystery solved? N Engl J Med 2009;361(1):81-3.

36 Salant DJ. In search of the elusive membranous nephropathy antigen. Nephron Physiol. 2009;112(1):p11-2.

37 Hoxha E, Wiech T, Stahl PR, Zahner G, Tomas NM, Meyer-Schwesinger C, et al. A mechanism for cancer-associated membranous nephropathy. N Engl J Med. 2016; 374(20):1995-6.

38 Taguchi S, Koshikawa Y, Ohyama S, Miyachi $\mathrm{H}$, Ozawa H, Asada H. Thrombospondin type-1 domain-containing 7A-associated membranous nephropathy after resection of rectal cancer: a case report. BMC Nephrol. 2019;20(1):43.

39 Prunotto M, Carnevali ML, Candiano G, Murtas C, Bruschi M, Corradini E, et al. Autoimmunity in membranous nephropathy targets aldose reductase and SOD2. J Am Soc Nephrol. 2010;21(3):507-19.

40 Debiec H, Lefeu F, Kemper MJ, Niaudet P, Deschênes G, Remuzzi G, et al. Early-childhood membranous nephropathy due to cationic bovine serum albumin. N Engl J Med. 2011;364(22):2101-10.

41 Jhaveri KD, Shah HH, Calderon K, Campenot ES, Radhakrishnan J. Glomerular diseases seen with cancer and chemotherapy: a narrative review. Kidney Int. 2013;84(1):34-4.

42 Schulze M, Donadio JV, Pruchno CJ, Baker PJ, Johnson RJ, Stahl RA, et al. Elevated urinary excretion of the C5b-9 complex in membranous nephropathy. Kidney Int. 1991; 40(3):533-8.

43 Debiec H, Nauta J, Coulet F, van der Burg M, Guigonis V, Schurmans T, et al. Role of truncating mutations in MME gene in fetomaternal alloimmunisation and antenatal glomerulopathies. Lancet. 2004;364(9441):1252-9.

44 Seikrit C, Ronco P, Debiec H. Factor H autoantibodies and membranous nephropathy. $\mathrm{N}$ Engl J Med. 2018;379(25):2479-81.

45 Valoti E, Noris M, Remuzzi G. More about factor $\mathrm{H}$ autoantibodies in membranous nephropathy. N Engl J Med. 2019;381(16): $1590-2$.

46 Segawa Y, Hisano S, Matsushita M, Fujita T, Hirose S, Takeshita M, et al. IgG subclasses and complement pathway in segmental and global membranous nephropathy. Pediatr Nephrol. 2010;25(6):1091-9.

47 Lhotta K, Würzner R, König P. Glomerular deposition of mannose-binding lectin in human glomerulonephritis. Nephrol Dial Transplant. 1999;14(4):881-6.

48 Bacchetta J, Juillard L, Cochat P, Droz JP. Paraneoplastic glomerular diseases and malignancies. Crit Rev Oncol Hematol. 2009; 70(1):39-58.
49 Lefaucheur C, Stengel B, Nochy D, Martel P, Hill GS, Jacquot C, et al. Membranous nephropathy and cancer: epidemiologic evidence and determinants of high-risk cancer association. Kidney Int. 2006;70(8):1510-7.

50 Beck LH. Membranous nephropathy and malignancy. Semin Nephrol. 2010;30(6):635-44.

51 Bobart SA, De Vriese AS, Pawar AS, Zand L, Sethi S, Giesen C, et al. Noninvasive diagnosis of primary membranous nephropathy using phospholipase A2 receptor antibodies. Kidney Int. 2019;95(2):429-38.

52 Rovin BH, Almaani S, Malvar A. Reimagining the kidney biopsy in the era of diagnostic biomarkers of glomerular disease. Kidney Int. 2019;95(2):265-7.

53 Ruggenenti P, Mosconi L, Vendramin G, Moriggi M, Remuzzi A, Sangalli F, et al. ACE inhibition improves glomerular size selectivity in patients with idiopathic membranous nephropathy and persistent nephrotic syndrome. Am J Kidney Dis. 2000;35:381-91.

54 Ruggenenti P, Fervenza FC, Remuzzi G. Treatment of membranous nephropathy: time for a paradigm shift. Nat Rev Nephrol. 2017;13(9):563-79.

55 Kosmadakis G, Filiopoulos V, Georgoulias C, Tentolouris N, Michail S. Comparison of the influence of angiotensin-converting enzyme inhibitor lisinopril and angiotensin II receptor antagonist losartan in patients with idiopathic membranous nephropathy and nephrotic syndrome. Scand J Urol Nephrol. 2010;44(4):251-6.

56 Lee T, Biddle AK, Lionaki S, Derebail VK, Barbour SJ, Tannous S, et al. Personalized prophylactic anticoagulation decision analysis in patients with membranous nephropathy. Kidney Int. 2014;85(6):1412-20.

57 Glassock RJ. Prophylactic anticoagulation in nephrotic syndrome: a clinical conundrum. J Am Soc Nephrol. 2007;18(8):2221-5.

58 Floege J, Barbour SJ, Cattran DC, Hogan JJ, Nachman PH, Tang SCW, et al. Management and treatment of glomerular diseases (part 1): conclusions from a Kidney Disease: Improving Global Outcomes (KDIGO) Controversies Conference. Kidney Int. 2019;95(2):26880.

59 van den Brand JAJG, Ruggenenti P, Chianca A, Hofstra JM, Perna A, Ruggiero B, et al. Safety of rituximab compared with steroids and cyclophosphamide for idiopathic membranous nephropathy. J Am Soc Nephrol. 2017;28(9):2729-37.

60 Howman A, Chapman TL, Langdon MM, Ferguson C, Adu D, Feehally J, et al. Immunosuppression for progressive membranous nephropathy: a UK randomised controlled trial. Lancet. 2013;381(9868):744-51.

61 Jha V, Ganguli A, Saha TK, Kohli HS, Sud K, Gupta KL, et al. A Randomized, controlled trial of steroids and cyclophosphamide in adults with nephrotic syndrome caused by idiopathic membranous nephropathy. J Am Soc Nephrol. 2007;18(6):1899-904.
62 Ponticelli C, Zucchelli P, Passerini P, Cesana B, Locatelli F, Pasquali S, et al. A 10-year follow-up of a randomized study with methylprednisolone and chlorambucil in membranous nephropathy. Kidney Int. 1995;48(5): 1600-4.

63 Ponticelli C, Altieri P, Scolari F, Passerini P, Roccatello D, Cesana B, et al. A randomized study comparing methylprednisolone plus chlorambucil versus methylprednisolone plus cyclophosphamide in idiopathic membranous nephropathy. J Am Soc Nephrol. 1998;9(3):444-50.

64 du Buf-Vereijken PW, Branten AJ, Wetzels JF, Apperloo AJ, Berden JHM, van Hamersvelt $\mathrm{HW}$, et al. Cytotoxic therapy for membranous nephropathy and renal insufficiency: improved renal survival but high relapse rate. Nephrol Dial Transplant. 2004;19(5):1142-8.

65 Yuan J, Fang W, Zhang W, Ni Z, Qian J. Treatment of nephrotic idiopathic membranous nephropathy with monthly i.v. pulse cyclophosphamide and oral steroids: a single centre's retrospective study. Nephrology (Carlton). 2011;16(4):440-5.

66 Mathrani V, Alejmi A, Griffin S, Roberts G. Intravenous cyclophosphamide and oral prednisolone is a safe and effective treatment option for idiopathic membranous nephropathy. Clin Kidney J. 2017;10(4):450-4.

67 Praga M, Barrio V, Juárez GF, Luño J. Tacrolimus monotherapy in membranous nephropathy: a randomized controlled trial. Kidney Int. 2007;71(9):924-30.

68 Cattran DC, Appel GB, Hebert LA, Hunsicker LG, Pohl MA, Hoy WE, et al. Cyclosporine in patients with steroid-resistant membranous nephropathy: a randomized trial. Kidney Int. 2001;59(4):1484-90.

69 Chen M, Li H, Li XY, Lu FM, Ni ZH, Xu FF, et al. Tacrolimus combined with corticosteroids in treatment of nephrotic idiopathic membranous nephropathy: a multicenter randomized controlled trial. Am J Med Sci. 2010;339(3):233-8.

70 Caro J, Gutiérrez-Solís E, Rojas-Rivera J, Agraz I, Ramos N, Rabasco C, et al. Predictors of response and relapse in patients with idiopathic membranous nephropathy treated with tacrolimus. Nephrol Dial Transplant. 2015;30(3):467-74

71 Segarra A, Praga M, Ramos N, Polanco N, Cargol I, Gutierrez-Solis E, et al. Successful treatment of membranous glomerulonephritis with rituximab in calcineurin inhibitordependent patients. Clin J Am Soc Nephrol. 2009;4(6):1083-8.

72 Ruggenenti P, Cravedi P, Chianca A, Perna A, Ruggiero B, Gaspari F, et al. Rituximab in idiopathic membranous nephropathy. J Am Soc Nephrol. 2012;23(8):1416-25.

73 van de Logt AE, Dahan K, Rousseau A, van der Molen R, Debiec H, Ronco P, et al. Immunological remission in PLA2R-antibodyassociated membranous nephropathy: cyclophosphamide versus rituximab. Kidney Int. 2018;93(4):1016-7. 
74 Seitz-Polski B, Dahan K, Debiec H, Rousseau A, Andreani M, Zaghrini C, et al. High-dose rituximab and early remission in PLA2R1-related membranous nephropathy. Clin J Am Soc Nephrol. 2019 Aug 7;14(8):1173-82.

75 Cravedi P, Ruggenenti P, Sghirlanzoni MC, Remuzzi G. Titrating rituximab to circulating B cells to optimize lymphocytolytic therapy in idiopathic membranous nephropathy. Clin J Am Soc Nephrol. 2007;2(5):932-7.

76 Cattran DC, Alexopoulos E, Heering P, Hoyer PF, Johnston A, Meyrier A, et al. Cyclosporin in idiopathic glomerular disease associated with the nephrotic syndrome: workshop recommendations. Kidney Int. 2007;72(12): 1429-47.

77 Jacobs R, Langer-Jacobus T, Duong M, Stahl $\mathrm{K}$, Haller $\mathrm{H}$, Schmidt RE, et al. Detection and quantification of rituximab in the human urine. J Immunol Methods. 2017;451:11821.

78 Boyer-Suavet S, Andreani M, Cremoni M, Brglez V, Benzaken S, Bernard G, et al. Rituximab bioavailability in primary membranous nephropathy. Nephrol Dial Transplant. 2019 Aug 1;34(8):1423-5.

79 Dussol B, Morange S, Burtey S, Indreies M, Cassuto E, Mourad G, et al. Mycophenolate mofetil monotherapy in membranous ne- phropathy: a 1-year randomized controlled trial. Am J Kidney Dis. 2008;52(4):699-705.

80 Chan TM, Lin AW, Tang SC, Qian JQ, Lam MF, Ho YW, et al. Prospective controlled study on mycophenolate mofetil and prednisolone in the treatment of membranous nephropathy with nephrotic syndrome. Nephrology (Carlton). 2007;12(6):576-81.

81 Rauen T, Michaelis A, Floege J, Mertens PR. Case series of idiopathic membranous nephropathy with long-term beneficial effects of ACTH peptide 1-24. Clin Nephrol. 2009; 71(6):637-42.

82 Ponticelli C, Passerini P, Salvadori M, Manno C, Viola BF, Pasquali S, et al. A randomized pilot trial comparing methylprednisolone plus a cytotoxic agent versus synthetic adrenocorticotropic hormone in idiopathic membranous nephropathy. Am J Kidney Dis. 2006;47(2):233-40

83 van de Logt $\mathrm{AE}$, Beerenhout $\mathrm{CH}$, Brink $\mathrm{HS}$, van de Kerkhof JJ, Wetzels JF, Hofstra JM. Synthetic ACTH in high risk patients with idiopathic membranous nephropathy: a prospective, open label cohort study. PLoS One. 2015;10(11):e0142033.

84 Cang S, Mukhi N, Wang K, Liu D. Novel CD20 monoclonal antibodies for lymphoma therapy. J Hematol Oncol. 2012;5:64.
85 Barrett C, Willcocks LC, Jones RB, Tarzi RM, Henderson RB, Cai G, et al. Effect of belimumab on proteinuria and anti-phospholipase A2 receptor autoantibody in primary membranous nephropathy. Nephrol Dial Transplant. 2019;gfz086.

86 Hartono C, Chung M, Kuo SF, Seshan SV, Muthukumar T. Bortezomib therapy for nephrotic syndrome due to idiopathic membranous nephropathy. J Nephrol. 2014;27(1): 103-6.

87 Dahan K, Johannet C, Esteve E, Plaisier E, Debiec H, Ronco P. Retreatment with rituximab for membranous nephropathy with persistently elevated titers of anti-phospholipase A2 receptor antibody. Kidney Int. 2019;95(1): 233-4.

88 Cravedi $\mathrm{P}$, Sghirlanzoni $\mathrm{MC}$, Marasà $\mathrm{M}$, Salerno A, Remuzzi G, Ruggenenti P. Efficacy and safety of rituximab second-line therapy for membranous nephropathy: a prospective, matched-cohort study. Am J Nephrol. 2011; 33(5):461-8.

89 Cortazar FB, Leaf DE, Owens CT, Laliberte K Pendergraft WF, Niles JL. Combination therapy with rituximab, low-dose cyclophosphamide, and prednisone for idiopathic membranous nephropathy: a case series. BMC Nephrol. 2017;18(1):44-10. 